\title{
La idoneidad como condición estructural del sistema republicano constitucionalizado y la legitimación para su exigibilidad
}

\author{
The suitability as a structural condition of the \\ constitutionalized republican system and the \\ legitimacy for its enforceability \\ $A$ adequabilidade como condição estrutural do \\ sistema republicano constitucionalizado e a \\ legitimidade para sua exigibilidade
}

L'adéquation comme condition structurelle du système républicain constitutionnalisé et la légitimité de son caractère exécutoire 适合作为宪法化共和制度的结构条件及其可执行性的合法性

Marcelo José Schreginger ${ }^{1} \mid \begin{aligned} & \text { Universidad Nacional } \\ & \text { de La Plata }\end{aligned}$

Revista Derechos en Acción ISSN 2525-1678/ e-ISSN 2525-1686

Año 4/N 12 Invierno 2019 (21 junio a 20 septiembre), 210-245

DOI: https://doi.org/10.24215/25251678e306

ORCID: https://orcid.org/0000-0002-3958-8417

Recibido:05/03/2019

Aprobado: 09/06/2019

Resumen: El trabajo pone el eje en el respeto de la garantía de cobertura de cargos en dos premisas derivadas del artículo 16 de la Constitución Nacional: exigir idoneidad en los postulantes y habilitar a todos los habitantes de la Nación a demostrar tal requisito. Dicho postulado es considerado un principio estructural previsto en el programa constitucional inicial

\footnotetext{
1 Abogado, especialista en Derecho Administrativo (Universidad Nacional de La Plata), docente de posgrado de la Universidad Nacional de Rosario, juez de la Cámara en lo Contencioso Administrativo con asiento en San Nicolás de los Arroyos, provincia de Buenos Aires, Argentina. Email: marcelo_jose@yahoo.com
} 
como ínsito en el sistema republicano de gobierno constituyendo, tanto un derecho exigible por cada habitante del Estado como un deber para las autoridades de cada una de las esferas de gobierno que conforman nuestro sistema federal. Considera la previsión de cupos necesarios para resguardar a determinadas categorías desaventajadas -en muchos casos por prejuicios culturales que deben superarse- dentro de los cuales debe respetarse el principio de selección previsto constitucionalmente. Describe distintos fallos en los que se aborda la aplicación del requisito de idoneidad como exigencia en la cobertura de cargos públicos.

Palabras claves: Garantía de idoneidad. Igualdad en el acceso a los cargos públicos.Estabilidad.

Abstract: The present work is focused on respecting the guarantee of coverage of charges in two premises derived from article 16 of the National Constitution: demand suitability in the applicants and enable all the inhabitants of the Nation to demonstrate such a requirement. This postulate is considered a structural principle envisaged in the initial constitutional program as an inherent element in the republican system of government, constituting both an enforceable right for each inhabitant of the State and a duty for the authorities of each of the spheres of government that make up our federal system. It considers the provision of places necessary to protect the required disadvantaged categories - in many cases due to cultural prejudices that must be overcome - within which it must respect the constitutionally established selection principle. It describes different legal decisions in which the application of the suitability requirement is addressed as a requirement in the coverage of public charges.

Keywords: Suitability Guarantee-Equality in access to public office- permanence

Resumo: 0 trabalho coloca o eixo no respeito da garantia de cobertura de postos de trabalho em duas premissas derivadas do artigo 16 da Constituição Nacional: exigir a adequação dos postulantes e permitir a todos os habitantes da Nação demonstrar tal exigência. 0 referido postulado é considerado um princípio estrutural previsto no programa constitucional inicial como próprio do sistema republicano de governo constituindo tanto um direito exigível por cada habitante do Estado quanto um dever para as autoridades de cada uma das esferas de governo que compõem nosso 
sistema federal. Considera a provisão de quotas necessária para proteger certas categorias desfavorecidas - em muitos casos devido a preconceitos culturais que devem ser superados - dentro dos quais deve ser respeitado o princípio de seleção constitucionalmente estabelecido. Descreve diferentes decisões judiciais nas quais é abordada a aplicação do requisito de adequação como um requisito na cobertura de cobranças públicas.

Palavras-chave: Garantia de adequação. Igualdade no acesso à cargos públicos. Estabilidade.

Résumé: Ce travail se focalise sur le respect de la garantie de couverture des charges publiques suivant les deux prémisses qui découlent de I'article 16 de la Constitution Nationale: exiger des candidats l'adéquation au poste et permettre à tous les habitants de la Nation de pouvoir fournir les justificatifs requis. Ce postulat est considéré comme un príncipe structurel prévu par le programme constitutionnel inhérent au système républicain de gouvernement constituant, aussi bien en tant que droit exigible par tout citoyen qu'un devoir pour les autorités de chacune des sphères gouvernementales qui composent notre système fédéral. II considère la mise en place de quotas nécessaires pour proteger certaines catégories défavorisées - dans de nombreux cas en raison de leur propres préjugés culturels à surmonter - dans lesquels le principe de sélection prévu par la constitution doit être respecté. II décrit différentes failles sur l'application du príncipe d'exigence de la conformité au poste dans le processus de pourvoiement des charges publiques.

Mot-clés: Garantie de conformité. Égalité d'accès aux fonctions publiques Stabilité.

摘要: 这项工作将轴线置于 “国家宪法” 第16条规定的两个房地的保 险费保证范围内: 要求申请人适合并使所有居民能够证明这种要求。 所述假设被认为是初始宪法计划中预见的结构性原则, 当然在共和 制政体中, 既构成了国家每个居民的可执行权利, 也构成了构成我们 制度的每个政府领域当局的责任。联邦。它考虑提供保护某些弱势群 体所必需的配额 - 在许多情况下由于必须克服的文化偏见 - 必须遵 守宪法规定的选择原则。它描述了不同的失败, 其中适用性要求的应 用被作为公共收费范围的要求

关键字: 保证适用性, 获得公职的平等, 稳定性. 


\section{Introducción}

La protección del empleo público desde el derecho constitucional, laboral, e incluso en el derecho administrativo, apoyados en el Constitucionalismo social, se ha focalizado en la aplicación de la garantía de estabilidad consagrada en el artículo 14 bis de la Constitución Nacional y, mucho antes en el artículo 103 inciso 12 de la Constitución de la Provincia de Buenos Aires, lo que ha sido una herramienta más que trascendente para apuntalar la carrera profesional administrativa asegurando continuidad en las expectativas de crecimiento profesional, ello ante un posible riesgo de sustitución de los cuadros organizacionales por los sucesivos cambios de gestión que, la natural y sana alternancia democrática genera en los distintos órganos y entes estatales.

La idoneidad no sólo condiciona el derecho al acceso a la función pública, también constituye un requisito previo para el ejercicio regular de otros derechos o la consolidación de garantías vinculadas con la relación de empleo público -v. gr. el derecho a la estabilidad en el cargo previsto en el artículo 14 bis de la Constitución Nacional o a la carrera administrativa consagrado en el artículo 103 inciso 12 de la Constitución de la Provincia de Buenos Aires-. Así también respecto del cumplimiento de normas protectorias de determinadas categorías cuando las normas consagran políticas de inclusión laboral dentro de la organización pública.

En el presente trabajo planteamos que el requisito previo consagrado en la Constitución nacional en su artículo 16 constituye una condición basal para conformar la estructura organizacional estatal y para acceder a otras garantías o consolidar derechos, para lo cual el Estado tiene un deber positivo exigible de cubrir cada uno de los puestos gubernamentales respetando un mecanismo que garantice la posibilidad para todos los habitantes de nuestro país de acceder a los cargos públicos en igualdad de condiciones con un solo condicionante ineludible, la comprobación objetiva de idoneidad. 
Así también vamos a examinar el juego armónico y sistemático de ambas garantías (y deberes institucionales) y la incidencia de dicha interacción en la conformación de los cuadros estatales, por otro lado abordaremos la respuesta jurisprudencial a conflictos vinculados con el ingreso a los cuadros del estado.

\title{
II. La idoneidad para el acceso a los cargos públicos
}

\author{
Esta garantía consagrada en la Constitución desde su géne- \\ sis en el año $1853^{2}$, tiene una doble función; por un lado, poner
}

2 El requisito de idoneidad para el acceso a los cargos públicos no ha sido extraído del proyecto de Constitución para la Confederación Argentina de Juan Bautista Alberdi, ya que el artículo 17 establecía: "La ley no reconoce diferencia de clase ni persona. No hay prerrogativas de sangre, ni de nacimiento; no hay fueros personales; no hay privilegios, ni títulos de nobleza. Todos son admisibles a los empleos. La igualdad es la base del impuesto y de las cargas públicas. La ley civil no reconoce diferencia de extranjeros y nacionales."

Tampoco surgen sus fuentes de los debates de la Asamblea Constituyente. (cfr. DE ANGELIS, Pedro, "Asambleas Constituyentes Argentinas", t.IV 1827-1862, Bs. As., Talleres S.A. Casa Jacobo Peuser. Ltda.., 1937, p. 514-515).

Para Néstor Sagües el artículo tiene dos antecedentes precisos, uno próximo a la Constitución, éste es el proyecto de Pedro de Ángelis, quien en la sección cuarta artículo 14, expresaba: "Los argentinos son iguales ante la ley, y pueden obtener los empleos públicos a que aspiren, si tienen las aptitudes necesarias para desempeñarlos", otro lejano pero de enorme importancia, en el artículo VI de la Declaración de los derechos del hombre y del ciudadano (1789), norma que establecía: "La ley es la expresión de la voluntad general... Todos los ciudadanos, siendo iguales a sus ojos, son igualmente admisibles a todas las dignidades, puestos y empleos públicos, según su capacidad y sin otras distinciones que las de sus virtudes y talentos" (Cfr. SAGÜÉS, Néstor P. , "Sobre la reglamentación del principio constitucional de idoneidad", LL 1980-C-1216).

De igual manera Mario A. Midón señala que el artículo no abreva en ninguno de los estatutos o proyectos de la Constitución Nacional a partir de 1811, tampoco fue pensada por los convencionales norteamericanos ni incluida en el proyecto de Alberdi. Entiende que la interpretación que mejor se compatibiliza es aquella que entiende que los constituyentes se basaron en la declaración francesa de 1793 en cuanto consagraba la igualdad en la admisibilidad de los empleos públicos sujetos a "la consideración de virtudes y talentos que guían a las naciones libres en sus elecciones...", así también cita al proyecto de Pedro De Ángelis (MIDÓN, Mario A., "Consideraciones en torno a la idoneidad y el empleo público", LL 1983-A-920).

Lo que queda claro es que su antecedente ha sido el constitucionalismo francés posrevolucionario, podemos ver como el texto del artículo 10 de la Constitución Francesa de 1848 tiene gran similitud con el de nuestro artículo 16. El mismo establece: "Todos los ciudadanos 
en un pie de igualdad a todos los habitantes de la República y, por el otro, imponer al propio Estado la exigencia de condiciones de idoneidad suficientes a los postulantes para acceder a los cargos a cubrir, lo que supone limitar la discrecionalidad en la selección y procurar una gestión pública más eficiente ${ }^{3}$.

La exigencia del requisito de idoneidad en condiciones de igualdad no solo debe respetarse en cada uno de sus poderes, sino también en los distintos niveles de la organización federal, esto es: nacional, local y comunal.

\section{Consagración expresa del derecho al empleo en las Constituciones Locales}

La previsión constitucional de acceso igualitario a los cargos públicos con la sola exigencia de la idoneidad que contiene el artículo 16 de la Constitución Nacional debe ser respetada por todas las jurisdicciones locales en virtud de lo dispuesto por el artículo 5 de la Carta Federal, dado que es una de las garantías consagradas en dicha norma.

Sin perjuicio de ello, las Constituciones locales han profundizado las exigencias para resguardar el acceso a los cargos públicos y definir los parámetros sobre los que debe regularse el régimen de empleo público de los cuadros administrativos, como ejemplo de ello podemos citar los casos de las Provincias de Buenos Aires y Santa Fe, así también -más recientementeel de la Ciudad Autónoma de Buenos Aires.

\footnotetext{
son admisibles por igual a todos los empleos públicos, sin otro motivo de preferencia que sus méritos, y conforme a las condiciones que establezcan las leyes. Quedan abolidos para siempre todo título nobiliario, toda distinción de nacimiento, de clase o de casta" (Fuente: JÈZE, Gastón, "Principios..."; cit., t.Il.2., p. 35), frente al nuestro: "La Nación Argentina no admite prerrogativas de sangre, ni de nacimiento: no hay en ella fueros personales ni títulos de nobleza. Todos sus habitantes son iguales ante la ley, y admisibles en los empleos sin otra condición que la idoneidad. La igualdad es la base del impuesto y de las cargas públicas.", con el plus, para nuestra Carta Magna, de reconocer dicha garantía a todos sus habitantes sin exigir la condición de ciudadanos.

3 BIELSA, Rafael, “Derecho Administrativo”, t.III, Sexta Edición, La Ley, Bs. As., 1964, p. 98.
} 
La exigencia de idoneidad ha sido receptada en la Provincia de Buenos Aires a través del artículo 103 inciso $12^{4}$ de su Constitución, norma que a su vez, se integra con el inciso $3^{5} \mathrm{del}$ mismo artículo y con el artículo $39^{6}$ incorporado por la reforma del año 1994.

Cabe observar que el texto vigente del artículo 103 se corresponde con el del artículo 90 de la Constitución de 1934. En esta norma se reconoce no sólo el acceso por idoneidad, sino también otros componentes de la carrera administrativa, como la necesidad de disponer un escalafón (lo que supone la posibilidad de ascender), la uniformidad de sueldos por categoría y la

4 Artículo 103 inciso 12 de la Constitución de la Provincia de Buenos Aires: "Corresponde al Poder Legislativo:... 12.- Organizar la carrera administrativa con las siguientes bases: acceso por idoneidad; escalafón; estabilidad; uniformidad de sueldos en cada categoría e incompatibilidades."

5 Artículo 103 de la Constitución de la Provincia de Buenos Aires: “Corresponde al Poder Legislativo:... 3.- Crear y suprimir empleos para la mejor administración de la Provincia, determinando sus atribuciones, responsabilidades y dotación, con la limitación a que se refiere el primer párrafo del inciso anterior."

6 Artículo 39 de la Constitución de la Provincia de Buenos Aires: “El trabajo es un derecho y un deber social.

1. En especial se establece: derecho al trabajo, a una retribución justa, a condiciones dignas de trabajo, al bienestar, a la jornada limitada, al descanso semanal, a igual remuneración por igual tarea y al salario mínimo, vital y móvil.

A tal fin, la provincia deberá: fiscalizar el cumplimiento de las obligaciones del empleador y ejercer en forma indelegable el poder de policía en materia laboral; propiciar el pleno empleo, estimulando la creación de nuevas fuentes de trabajo; promover la capacitación y formación de los trabajadores; impulsar la colaboración entre empresarios y trabajadores, y la solución de los conflictos mediante la conciliación, y establecer tribunales especializados para solucionar los conflictos de trabajo.

2. La provincia reconoce los derechos de asociación y libertad sindical, los convenios colectivos, el derecho de huelga y las garantías al fuero sindical de los representantes gremiales.

3. En materia laboral y de seguridad social regirán los principios de irrenunciabilidad, justicia social, gratuidad de las actuaciones en beneficio del trabajador, primacía de la realidad, indemnidad, progresividad y, en caso de duda, interpretación a favor del trabajador.

4. Sin perjuicio de lo establecido en el art. 103, inc. 12 de esta Constitución, la provincia garantiza a los trabajadores estatales el derecho de negociación de sus condiciones de trabajo y la sustanciación de los conflictos colectivos entre el Estado provincial y aquellos a través de un organismo imparcial que determine la ley. Todo acto o contrato que contravenga las garantías reconocidas en el presente inciso será nulo." 
garantía de estabilidad, ello veintitrés años antes de la reforma que incorporara el artículo 14 bis a la Constitución Nacional.

Por otra parte, a partir del año 1994, en el caso de la Provincia de Buenos Aires, el trabajador encuentra garantías en el artículo 39 de su Constitución que protege concretamente la relación de empleo, debiendo entenderse que lo hace respecto de aquellas de naturaleza pública, ya que éstas son las únicas que pueden ser reguladas substancialmente por la autoridad provincial, ello debido a que las jurisdicciones locales no pueden incursionar en cuestiones laborales de fondo por ser materia excluida por el artículo 75 inciso 12 la Constitución Nacional.

El artículo 39 de la Constitución de la Provincia de Buenos Aires luego de enunciar en su inciso 1 que el trabajo es un derecho y un deber social -entre los diversos derechos que precisa- consagra expresamente el derecho "al trabajo".

Esta norma no sólo protege derechos derivados del ejercicio de la relación sustancial de empleo público en sí, sino que también garantiza el cumplimiento de atribuciones de la Provincia en materia de control e impone la carga de desarrollar actividades positivas directas o indirectas de fomento laboral.

Si bien el inciso 1 del artículo 39 en general, enuncia garantías protectorias del ejercicio de la relación de empleo público, al consagrar el derecho al empleo, lo hace como garantía programática, asignando a la Provincia competencia positiva (lo que supone potestades-deberes) destinada a garantizar la implementación de políticas públicas de promoción del empleo -lo que debe entenderse- como abarcativas tanto del ámbito público como privado.

La Constitución de Santa Fe en su artículo 55 inciso $23^{7}$ si bien no hace mención a la garantía de idoneidad sí lo hace

\footnotetext{
7 Artículo. 55 de la Constitución de la Provincia de Santa Fe: “Corresponde a la Legislatura: ...23- Dictar leyes sobre organización de la Administración pública y el estatuto de los funcionarios y empleados públicos, que incluya, entre otras, garantías de ingreso, estabilidad, carrera e indemnización por cesantía injustificada...".
} 
respecto a brindar garantías de ingreso, a la estabilidad y a contar con una carrera administrativa, sin perjuicio que posteriormente, hace mención al derecho a indemnización por cesantía injustificada.

El artículo $43^{8}$ de la Constitución de la Ciudad Autónoma de Buenos Aires, respecto del régimen de empleo público, reconoce las garantías de estabilidad y capacitación, todo ello bajo el principio de idoneidad funcional, así también la exigencia de regular la carrera administrativa y el acceso a los cargos a través de concurso público abierto. Esta manda -a diferencia de otras jurisdicciones que lo hacen a través de normas subconstitucionales- garantiza un cupo de un cinco por ciento para las personas con necesidades especiales.

\section{La garantía de acceso a los cargos públicos en el derecho supranacional}

Tanto la Convención Interamericana contra la Corrupción ${ }^{9}$ -aprobada por Ley 24.759- como la Convención de las Naciones

8 Artículo 43 de la Constitución de la Ciudad Autónoma de Buenos Aires: “La Ciudad protege el trabajo en todas sus formas. Asegura al trabajador los derechos establecidos en la Constitución Nacional y se atiene a los convenios ratificados y considera las recomendaciones de la Organización Internacional del Trabajo. La Ciudad provee a la formación profesional y cultural de los trabajadores y procura la observancia de su derecho a la información y consulta.

Garantiza un régimen de empleo público que asegura la estabilidad y capacitación de sus agentes, basado en la idoneidad funcional. Se reconocen y organizan las carreras por especialidad a las que se ingresa y en las que se promociona por concurso público abierto. Asegura un cupo del cinco por ciento del personal para las personas con necesidades especiales, con incorporación gradual en la forma que la ley determine. En todo contrato de concesión de servicios o de transferencia de actividades al sector privado, se preverá la aplicación estricta de esta disposición.

Reconoce a los trabajadores estatales el derecho de negociación colectiva y procedimientos imparciales de solución de conflictos, todo según las normas que los regulen.

El tratamiento y la interpretación de las leyes laborales debe efectuarse conforme a los principios del derecho del trabajo."

9 Artículo III: “Medidas preventivas. A los fines expuestos en el art. II de esta Convención, los Estados Partes convienen en considerar la aplicabilidad de medidas, dentro de 
Unidas contra la Corrupción ${ }^{10}$-aprobada por Ley 26.097- procuran garantizar el respeto de determinados principios en los procesos de selección de los agentes estatales. Estas convenciones -sin perjuicio de no haber sido constitucionalizadas hasta la fecha por no haberse cumplido con el requisito del artículo 75 inciso 22 "último párrafo" de la Constitución Nacional-, resultan de aplicación a las Provincias por ser leyes que reglamentan directamente derechos consagrados en la primera parte de la Constitución Nacional, resguardadas en las Provincias en virtud de la garantía federal del artículo 5 de la Carta Federal.

La Convención Interamericana contra la Corrupción en su artículo 3 punto 5 prevé que cada Estado debe considerar la aplicación de sistemas de contratación de funcionarios públicos que aseguren publicidad, equidad y eficiencia.

La publicidad ${ }^{11}$ supone adecuada difusión de la necesidad y requisitos para la cobertura del cargo y al consumarse, también de la designación.

La equidad en el sistema de contratación de empleados públicos puede ser entendida como pauta de razonabilidad en situaciones de contrataciones desmedidas, es decir como límite intrínseco a la discrecionalidad. Así también como pauta de moderación en la aplicación de la ley ${ }^{12}$, sentido receptado

sus propios sistemas institucionales, destinadas a crear, mantener y fortalecer: ...5. Sistemas para la contratación de funcionarios públicos y para la adquisición de bienes y servicios por parte del Estado que aseguren la publicidad, equidad y eficiencia de tales sistemas."

10 Artículo 7 Sector público 1. "Cada Estado Parte, cuando sea apropiado y de conformidad con los principios fundamentales de su ordenamiento jurídico, procurará adoptar sistemas de convocatoria, contratación, retención, promoción y jubilación de empleados públicos y, cuando proceda, de otros funcionarios públicos no elegidos, o mantener y fortalecer dichos sistemas. Éstos: a) Estarán basados en principios de eficiencia y transparencia y en criterios objetivos como el mérito, la equidad y la aptitud..."

11 GORDILLO, Agustín, “Un corte transversal al derecho administrativo: La Convención Interamericana contra la Corrupción", publicado en LL 1997-E-1091.

12 BREBBIA, Roberto H., "La equidad en el derecho de daños" en obra colectiva "Responsabilidad por Daños en el Tercer Milenio (Homenaje a Atilio A. Alterini)" Lexis N 1010/001395 (fuente pág. Web: www.lexisnexis.com.ar) define: Entendemos que la equidad, en virtud de la función ordenadora que cumple dentro del proceso de aplicación de la ley, permite 
expresamente por el artículo 117 decreto ley 7647/70 de procedimiento administrativo en la Provincia de Buenos Aires para limitar el rigor legal en la anulación de actos administrativos. Pero, sobre todo, el principio actúa como parámetro de justicia distributiva, más que en la subsunción de una norma al caso concreto de selección (v. gr. en la ponderación de los distintos requisitos de idoneidad en un supuesto específico) ${ }^{13}$, como criterio rector en la planificación general para la creación y cobertura de cargos públicos ${ }^{14}$. La equidad actúa aquí como regla directriz en el ejercicio de la función normativa del Estado destinada a aplicar políticas de inclusión social respecto de determinadas categorías que se encontrarían "a priori" en una supuesta desventaja para acceder al empleo, ejemplo concreto de ello lo tenemos en los casos de los discapacitados o de personas condenadas liberadas; así también en los casos de ejecución de políticas de ocupación en situación de emergencia por índices elevados de desempleo o categorías con

simplemente moderar 0 atenuar su rigor en la tarea de adecuar la regla abstracta a la singularidad fáctica, supliendo en la medida de lo posible aquella modalidad constitutiva derivada de la naturaleza general y abstracta de la ley.

13 RABBI BALDI CABANILLAS, Renato, "Actualidad sobre la jurisprudencia "De equidad" en la Corte Suprema de Justicia", LL-1999-F, p. 1148. Este autor distingue cuatro tipos de equidad tres tipos de equidad: aequitas griega, aequitas romana, la aequitas romana de la tradición cristiana y la equidad del control de constitucionalidad. La primera destinada a resolver en el caso concreto los supuestos que no ha podido contemplar la norma, de acuerdo a la segunda equidad es el derecho comprendido en el caso concreto, la tercera se corresponde con la modulación de la segunda por influencia correctora de la moral judeo-cristiana. A través de la cuarta sino que se la cual se declara inaplicable para el caso o se la expulsa del ordenamiento, aplicando una norma de rango superior; a diferencia del primer supuesto no se resuelve una situación no contemplada sino que se excluye su solución.

14 RABBI BALDI CABANILLAS, Renato, "Actualidad sobre la jurisprudencia "De equidad" ... citado p. 1148. En su trabajo el autor ejemplifica como los criterios de equidad para la resolución del caso, pueden luego positivizarse como principios o reglas. La equidad en sus diferentes variantes responde a distintos criterios de justicia para el caso concreto. Entiendo que el sentido de equidad como pauta de política legislativa, responde, en verdad, a un criterio axiológico, que, en el caso debe ser consecuente con el programa valorativo plasmado en la Constitución de la Provincia de Buenos Aires que, en líneas generales responde a una concepción social del Estado de Derecho, que en la materia abordada se ve reflejado en la consagración expresa del derecho al trabajo en el artículo 39 punto 1 de la Carta Provincial. 
mayores dificultades para acceder al mismo (v. gr. a través de planes específicos y temporales, como los denominados "planes trabajar") ${ }^{15}$.

La eficiencia es un principio básico organizacional proveniente de las ciencias económicas que, desde su visión, tiene por objeto maximizar la utilización de los recursos para obtener con ello los mayores resultados, en cambio el principio de eficacia procura como objetivo principal maximizar los resultados.

Ambas convenciones exigen eficiencia en la contratación de empleados públicos.

Dicha eficiencia puede ser considerada desde dos puntos de vista: en el proceso de selección y en el desarrollo de la función. Pero, es en este último donde adquiere su real dimensión, ya que, exigir eficiencia en el agente público redundará en eficiencia para la propia administración. Sin embargo, también debe influir este principio en el proceso de selección, tanto para determinar las condiciones de idoneidad de quien debe cubrir el cargo, como en el desarrollo del procedimiento en sí, fundamentalmente, si ello va de la mano de otros principios como los de transparencia, concurrencia (éste y el anterior vinculados también con el de publicidad) y competencia objetiva -v. gr. concurso de oposición y antecedentes-.

La Convención de las Naciones Unidas contra la Corrupción en su artículo 7 punto 1 prevé que cada Estado parte debe procurar adoptar sistemas de convocatoria y contratación de empleados públicos basados en principios de eficiencia, transparencia, criterios objetivos de mérito, equidad y aptitud.

\footnotetext{
15 Cabe destacar que a través de distintas normas -sobre todo de carácter local- se procuró brindar un cupo laboral a ex combatientes de Malvinas, tal el caso de la Ley 3281/87 de la Provincia de Chaco o de la, ordenanza "de facto" 37945/82 de la Ciudad de Buenos Aires, en ambos casos disponiendo la cobertura de cargos para ello y eximiendo de los requisitos previstos normativamente para cubrir los mismos. En cambio, la Ley 2534/85 de la Provincia de Chubut previó una prioridad para los ex combatientes por el término de dos años, respetando los requisitos de idoneidad. En estos casos, los motivos para priorizar al grupo pudieron ser tanto de equiparación frente a casos de dificultad en el acceso al empleo como también como forma de reconocimiento social.
} 
Esta Convención ha dado varios pasos más que la CICC, ya que exige sistemas de convocatoria y transparencia en la selección, lo que supone un grado de difusión y control mucho mayor que el que garantiza la sola publicidad.

Por otra parte, el principio de eficiencia, debe estar respaldado con la selección de funcionarios en virtud de criterios objetivos de mérito y acreditación de aptitud.

Junto a todos estos principios -de la misma manera que la CICC- esta Convención exige el resguardo del principio de equidad.

\section{Autolimitación normativa}

Junto al esquema sentado por el marco constitucional y convencional supranacional, los distintos regímenes de empleo público previstos en las normas señalan mecanismos de ingreso en base a pautas de selección objetivas por mérito y exigen la comprobación de aptitud para el cargo.

Puntualmente, en la Provincia de Buenos Aires, tanto la Ley 10.430 -régimen general-, como los estatutos especiales lo han regulado en este sentido.

Esta autolimitación se traduce en la exigencia -como deber para la Administración Pública- de cumplir con las previsiones normativas en la selección de personal, pero también en un derecho jurídicamente protegido para quienes pretenden acceder a los cargos vacantes.

A su vez la propia Administración puede autolimitarse a través de su potestad reglamentaria, no pudiendo excepcionarse a través de actos concretos de sus disposiciones de naturaleza normativa ${ }^{16}$.

16 GARCÍA DE ENTERRÍA, Eduardo, Editorial Civitas Ediciones S.L., Madrid, 2000, t.l., p. 204. Principio de inderogabilidad singular de los reglamentos. "La autoridad que ha dictado un reglamento y que, por lo tanto, podría igualmente derogarlo, no puede, en cambio, mediante un acto singular excepcionar su para un caso concreto la aplicación del Reglamento, a menos que, naturalmente, este mismo autorice la excepción o dispensa." 


\section{Definición de idoneidad}

La idoneidad supone capacidad ${ }^{17}, \operatorname{condició}^{18}{ }^{18} \operatorname{aptitud}^{19} \mathrm{o}$ suficiencia ${ }^{20}$ para desempeñar un empleo.

Comúnmente, si bien, en una primera aproximación, se vincula a la idoneidad con la capacidad técnica ${ }^{21}$, condiciones profesionales o habilidades intelectuales para desarrollar una tarea, profesión u oficio, ésta no es la única acepción del término a los fines de la ponderación de las condiciones de una persona para el ingreso a la función pública, este mayor alcance es el que debe inferirse del texto constitucional.

Para Fiorini ${ }^{22}$, la expresión idoneidad es de tipo genérico, para su determinación concurren diferentes valores con distinto contenido. Señala que el término ha sido proclive a consideraciones de orden técnico, ético, político, entre otras.

Él ha entendido que: "La idoneidad en nuestro país se fundamenta en los valores de la argentinidad, contenido de respeto por la divinidad humana, culto a los elevados valores del ser humano, razón en el juicio, ética en la conducta, lealtad en los procederes, entrega generosa a la comunidad, probidad en el

17 SAGÜES, Néstor, "La reglamentación del principio constitucional de idoneidad" LL 1980C-1216 hace referencia a esta cualidad con cita y referencia de BIELSA, Rafael, "Derecho Constitucional" 3ed. Editorial Depalma Bs.As. 1959 p. 262.

18 BIELSA, Rafael, “Derecho ...", cit., t.III., p. 99.

19 MARIENHOFF, Miguel S., "Tratado de Derecho Administrativo", Tomo III-B, AbeledoPerrot $4{ }^{a}$ ed. actualizada, Buenos Aires, 1998, parágrafo 879, p. 120.

20 VILLEGAS BASAVILBASO, "Derecho Administrativo", t. III., Tipografía Editora Argentina Bs. As., 1951, p. 363. Este autor señala que la acepción idiomática de idoneidad es la de suficiencia para una cosa. Luego cuando distingue sus distintas facetas habla de aptitudes: técnica, física, moral (p. 366).

21 BIELSA, Rafael, “Derecho...", cit., t. III, p. 104. Este autor señala que: “Si bien, según el texto constitucional, la idoneidad es condición general para desempeñar un empleo o función pública, el concepto de idoneidad, aunque referido principalmente a la aptitud técnica del agente, tiene un significado más general, pues comprende no sólo la aptitud física y legal, sino su aptitud político moral."

22 FIORINI, Bartolomé A., "Derecho Administrativo", t. I, Editorial Abeledo Perrot, 2da. Edición 1976, p. 795. 
ejercicio de la función, cumplimiento de los deberes impuestos y amor a la patria". Esta concepción tiene un gran contenido ético y resulta gratificante adscribir a ella, lo que exige procurar su cumplimiento como requisito para el ejercicio de la función pública, más aún en una época donde nuestro país ha aprobado diferentes convenciones, sancionado leyes y reglamentado códigos destinados a marcar la conducta ética de sus funcionarios en sus diferentes niveles de organización político territorial.

Así también, desde una visión diferente, Gastón Jèze exigía para cubrir un cargo público inteligencia, probidad, conocimientos técnicos, celo y sacrificio por la cosa pública ${ }^{23}$. Condiciones deseables de encontrar en un agente del estado siempre que fueran unidas a las expuestas por el maestro Fiorini.

Constituye principio de derecho constitucional y administrativo $^{24}$ que la idoneidad, en sus diferentes facetas, no se presume y, en consecuencia, debe probarse ${ }^{25}$. Esto supone limitar la potestad discrecional de quien nombra, quien debe acreditar en el acto de designación los fundamentos de la selección.

\section{Reglamentación del requisito de la idoneidad}

De acuerdo al artículo 14 de la Constitución Nacional todos los derechos son relativos, en tanto se ejercen conforme a las leyes que reglamentan su ejercicio bajo el límite de la razonabilidad (artículo 28 de la Constitución Nacional).

La necesidad de regular las distintas manifestaciones del requisito de idoneidad ha sido puesta en duda respecto de los

\footnotetext{
23 JÈZE, Gastón, “Principios Generales del Derecho Administrativo", t. II.2. Editorial Desalma, Buenos Aires, 1949, p. 6.

24 SAGÜES, Néstor, "La reglamentación..." cit., p. 1216.

25 BIELSA, Rafael, "Derecho...", cit., t.III, p.99. Ha expresado que: "La idoneidad o suficiencia no se presume, ella debe probarse de acuerdo con las formas legales, que - como se comprende - deben prevalecer sobre las facultades discrecionales de la autoridad que nombra, y en su virtud considera o juzga la idoneidad; no bastan las apreciaciones de visu, muy propias de nuestro 'sistema'."
} 
cargos previstos en la Constitución Nacional, no así respecto de los restantes cargos, donde la situación es más que clara.

Respecto a la discusión señalada en primer término se han dividido las posiciones en dos grandes grupos, aquellos que consideran que pueden imponerse otros requisitos que los previstos en la Carta Magna ${ }^{26}$ y quienes adoptan una postura restrictiva ${ }^{27}$.

Entendemos que, la Constitución como carta programática, no puede precisar todos los supuestos y exigencias que permitan la mejor cobertura de cargos, por más que éstos se correspondan con los más elevados de la organización nacional.

En este sentido el legislador podrá normar requisitos no previstos, siempre que estos sean razonables, no alteren las exigencias de igualdad e idoneidad, no se opongan o sean incompatibles con los ya previstos y no desnaturalicen la función.

Según Sagüés, no resulta razonable negar otros requisitos no enumerados por la Constitución, inspirados en razones de bien común, moralidad pública, eficiencia y sensatez. Da como ejemplo exigir una determinada capacidad elemental (como mínimo ciclo primario completo ${ }^{28}$, determinar la exclusión de los alienados, menores de edad, sordomudos o quebrados fraudulentos o excluir a quienes han cometido delitos dolosos de determinada gravedad, para acceder a los cargos previstos en

\footnotetext{
26 SAGÜES, Néstor, "La reglamentación del principio constitucional de idoneidad" LL 1980C-1216; MIDÓN, Mario A., “Consideraciones en torno a la idoneidad y el empleo" LL 1983-A920; BADENI, Gregorio, Instituciones de Derecho Constitucional, Editorial Ad-Hoc SRL, Bs. As. 1999 p. 216.

27 BIDART CAMPOS, Germán, "Tratado Elemental de Derecho Constitucional Argentino", t. I, Editorial Ediar Bs.As. 1993, p. 392; EKMEKDJIAN, Miguel Ángel, “Tratado de Derecho Constitucional", t. II, Editorial Desalma, Bs. As.1994 p. 130.

28 MIDÓN, Mario A. en su trabajo "Consideraciones en torno..." cit., entiende que no resulta irrazonable exigir para las altas magistraturas del Estado -exceptuados los miembros de la Corte y demás tribunales, para quienes es exigible título universitario-, tenga por lo menos el ciclo secundario o equivalente cumplido.
} 
la Constitución (v. gr. Ministros, miembros de la Corte Suprema de Justicia, diputados o senadores) ${ }^{29}$.

Horacio Rosatti señala que no resulta inconstitucional reglamentar las condiciones de idoneidad por vía legal siempre que ello supere el test de razonabilidad ${ }^{30}$

Tampoco parece irrazonable exigir antecedentes de cumplimiento de acciones que evidencien comportamientos éticos socialmente corroborados ${ }^{31}$ o una conducta de lealtad democrática e institucional.

\section{Distintas facetas de la idoneidad}

La idoneidad como concepto genérico puede clasificarse de distintas maneras agrupando las características de los requisitos o condiciones exigidas para acceder a la función pública.

Bielsa ha distinguido la idoneidad legal de la profesional, la primera se corresponde con el cumplimiento formal de la ley, la segunda con los principios de la ciencia de la administración, aunque también debe tener base legal ${ }^{32}$.

A su vez, dentro de la idoneidad legal diferencia a las condiciones positivas de las negativas:

$1^{\circ}$ ) Las positivas exigen cumplir con determinados requisitos, como la de tener el título profesional, ciudadanía, edad, etc.

$2^{\circ}$ ) Las negativas suponen inhabilidades e incompatibilidades, por ejemplo, no sufrir inhabilitación por condena penal, no haber sido destituido por vía disciplinaria, o no haber incurrido en trasgresión legal de orden político o administrativo sancionada con la pérdida e interdicción de desempeñar

29 SAGÜES, Néstor, “La reglamentación del principio ..." cit., p. 1216..

30 ROSATTI, Horacio, "La idoneidad de acceso y de ejercicio de los representantes en los cargos políticos electivos", Revista de Derecho Público, 2012-2, Empleo Público II, Rubinzal Culzoni Editores, Buenos Aires - Santa Fe, 2012, p. 11.

31 MIDON, Mario A., “Consideraciones en torno..." cit., p. 520.

32 BIELSA, Rafael, "Derecho..." cit., t.III, p. 99 
función o empleo público. Distingue de éstas el concepto de solvencia moral.

Este autor también ha separado la aptitud técnica, de la física, legal y político moral ${ }^{33}$.

Miguel S. Marienhoff ha indicado que, en algunos casos también es necesario acreditar aptitud económica ${ }^{34}$.

Benjamín Villegas Basavilbaso ha señalado como requisitos de la idoneidad a la aptitud técnica (intelectual o profesional), aptitud física (edad o salud), la moralidad, el cumplimiento del servicio militar obligatorio y, en algunos casos, el requisito de ciudadanía $^{35}$. Desecha como requisitos, el sexo, las creencias religiosas o políticas.

Dentro de la aptitud moral cabe distinguir los supuestos de moralidad negativa (incompatibilidad o inhabilidad) de la exigencia de antecedentes de idoneidad positiva.

En este caso, como requisito de ingreso se requiere la acreditación de comportamientos virtuosos.

Es posible apreciar que las leyes que regulan los estatutos de empleo público difícilmente contemplen este tipo de antecedentes.

Sin embargo, podemos encontrar algunos ejemplos, tal el caso de la Ley 13.447 de la Provincia de Buenos Aires, que prevé como antecedente de valoración obligatoria para los concursos destinados a cubrir vacantes en los tres poderes del Estado Provincial al voluntariado social regulado en la Ley Nacional 25.855. Otro ejemplo lo encontramos en el Decreto 3.312/07, reglamentario de la Ley 13.714 de la Provincia de Buenos Aires que establecía un sistema de selección excepcional y temporario del personal de la administración pública provincial ${ }^{36}$,

\footnotetext{
33 BIELSA, Rafael, “Derecho...", cit., t.III, p. 104.

34 MARIENHOFF, Miguel S., Tratado...", cit., t.III-B., parágrafo 879, 120.

35 VILLEGAS, BASAVILBASO, Benjamín., “Derecho...", cit., t.III., p. 365.

36 Artículo 1 de la Ley 13417: "Suspéndase desde el $1^{\circ}$ de enero de 2007 y hasta el 31 de diciembre de 2009, inclusive, las normas contenidas en la Ley Nº 10430 (T.0. según Decreto
} 
allí, en el artículo $15^{37}$ de la norma reglamentaria citada, se definen los distintos tipos de competencia a evaluar para cubrir cargos vacantes, contemplando en primer lugar a la "ético institucional", en la que se incluye la ponderación de los valores y comportamientos observables y susceptibles de ponerse en práctica en el puesto de trabajo, y estos, concretamente, deben estar referidos al respeto de los derechos humanos e instituciones democráticas, a la búsqueda de la justicia y a la promoción de la inclusión social.

La exigencia de esta faceta de la idoneidad debe acentuarse respecto de la cobertura de aquellos cargos de mayor responsabilidad institucional.

№ 1869/96) y sus modificatorias, que se opongan a la presente, y al sólo efecto de la cobertura de cargos vacantes."

37 Artículo 15 del Decreto 3312/07: “En los procesos de selección se evaluarán tres tipos de Competencias:

* Competencias ético institucionales: Son valores que se manifiestan en comportamientos observables y susceptibles de ponerse en práctica en cada puesto de trabajo. Están referidos al respeto por los derechos humanos y las instituciones de la democracia, como así también a la búsqueda de la justicia y la promoción de la inclusión social en el diseño y ejecución de las políticas de Estado. El compromiso debe manifestarse, particularmente, en la institución estatal en la que se presta servicios, conociendo el Plan de Gobierno y/o el Plan estratégico o Institucional del organismo y reconociendo el rol indelegable del Estado en materia de integración social y promoción del desarrollo. Estas competencias son básicas y comunes a todos los grupos, sin perjuicio de otras específicas del mismo carácter que cada puesto demande.

* Competencias técnico profesionales: Son las competencias específicas y necesarias para el cumplimiento de las acciones correspondientes a un puesto de trabajo determinado. Comprenden: 1) Los conocimientos teóricos, metodológicos y técnicos adquiridos por formación profesional y/o la experiencia. 2) Las habilidades para la utilización de herramientas 0 instrumentos técnicos propios de una profesión, oficio o especialidad. 3) Las destrezas 0 entrenamientos físicos e intelectuales que permiten actuar con pericia, arte 0 ingenio, incluso en situaciones nuevas o no previstas.

* Competencias actitudinales: Son el conjunto de actitudes y estrategias que pone en juego un trabajador/ra para relacionarse con su entorno laboral y social. Incluye entre otras: capacidad para la integración de equipos; predisposición al cambio; proactividad, comunicación y propensión a la resolución constructiva de conflictos; capacidad de liderazgo y coordinación de tareas". 


\section{Derechos al empleo}

El derecho al empleo es aquel que permite reclamar a un individuo el acceso a un empleo público en forma previa a la constitución del vínculo.

El grado de expectativa puede tener diferentes niveles, podemos distinguir el del mero habitante, ciudadano o residente (según el caso), inscripto, postulante, concursante seleccionado, concursante o postulante propuesto, hasta arribar a quien ha sido designado.

El derecho al empleo legitima tanto a quien quiere acceder al proceso de selección, como a quienes, participando del mismo, exigen el cumplimiento de las reglas -que los rigen tanto a ellos como a sus oponentes-.

La posibilidad de ejercer estos derechos dependerá también del sistema de selección adoptado, siendo el concurso el que permite mayores posibilidades de identificación de los sucesivos afectados.

Si bien es discrecional la atribución de la Administración Pública para determinar sus necesidades de personal, así como la conformación de su planta a través de distintos niveles organizacionales -salvo en los casos en que determinados cargos sean previstos por la ley-, no lo es el mecanismo de selección conforme al plexo constitucional, supranacional, legal y, eventualmente reglamentario ${ }^{38}$.

38 CASSAGNE, Juan Carlos, "El Contrato Administrativo", Abeledo Perrot-LexisNexis, Buenos Aires, 2005, p. 98. .El llamado a concurso supone el dictado de un acto reglamentario que debe ser respetado, con cita de fallo 315:2899 (voto del Dr.Barra).

CJSN, sentencia del 10 de diciembre de 1992 en causa M. 141. XXIII. "Martín, Estela Delia Correa de c/ Universidad Nacional de San Juan s/ contenciosoaministrativo." Fallos: T. 315: 2899 (Magistrados Votantes: Levene, Fayt, Belluscio, Petracchi, Nazareno, Moliné O’Connor. Voto en disidencia: Barra. Abstención: Cavagna Martínez, Boggiano. Considerando 12) del voto en disidencia del Dr. Barra: “Que el establecimiento en los procesos de selección, ya sea concursales o licitatorios, de normas vinculadas a la comparación de oferentes o concursales, no resultan meras formalidades susceptibles de ser obviadas o de ser cumplidas de manera implícita o indirecta, como lo sostienen las recurrentes. Por el contrario, se trata de normas 
Dispuesta la necesidad de cobertura de un cargo, todo aquel que esté en condiciones de postularse puede hacer valer su derecho al empleo exigiendo el respeto del plexo normativo que lo garantiza.

Todo habitante tiene un derecho, no a obtener un cargo en particular, sino a exigir la cobertura de un cargo disponible por concurso, ello de acuerdo con el régimen que el Poder Legislativo debe regular en forma privativa por asignación constitucional.

La misma lógica cabe aplicar respecto de quien integrando ya la administración quiere crecer en la estructura organizacional frente a un cargo vacante, en este caso en su condición de agente, dispondrá de un derecho reconocido por la Constitución y por las diferentes leyes regulatorias de la relación de empleo público.

En este último caso no supone un derecho a detentar un cargo de mayor jerarquía, sino a postularse para el mismo, ya que dicho reconocimiento no implica desconocer la potestad de dirección que posee la Administración Pública respecto de su organización y planteles.

La idoneidad que se exige desde el ingreso en un pie de igualdad se mantiene como requisito organizacional para regular -y condicionar- otra de las garantías organizacionales de la estructura estatal, esto es la profesionalización de sus planteles y el incentivo a quienes lo integran a través de la posibilidad de tener una carrera que les permita crecer en la organización.

contenidas en un reglamento administrativo que tienden a homogeneizar los criterios de evaluación, permitiendo así tanto el control de legalidad por parte de la administración como el resguardo de los propios derechos de los participantes, que también requieren de datos objetivos a esos efectos. Se trata en definitiva, de garantizar los principios de publicidad -conocimiento de las razones tenidas en cuenta por la Administración-, competencia -pujar conforme a los mismos criterios de selección e igualdad -trato a todos los concursantes u oferentes sin discriminaciones ni preferencias subjetivas-, principios éstos esenciales a todo procedimiento administrativo de selección, y emanados de las garantías del debido proceso y de igualdad consagradas por los arts. 18 y 16 de la Constitución Nacional." 
El mecanismo que permite garantizar a todo habitante que quiera acceder a un cargo público en un pie de igualdad tratando de acreditar su idoneidad es, por antonomasia, el concurso ${ }^{39}$.

\section{Idoneidad y categorías diferenciadas}

Cuando abordamos el principio de equidad en la contratación pública, hicimos referencia a la decisión estatal de aplicar en materia de empleo público políticas de inclusión social respecto de determinadas categorías que se encontrarían "a priori" en una supuesta desventaja para acceder a un puesto de trabajo.

Nuestra constitución nacional ha asumido el compromiso de llevar adelante acciones positivas para asegurar igualdad real de oportunidades y de trato para todos los habitantes, en general en el inciso $19^{40}$ del artículo 75 y respecto de determinadas

39 BUTELER, Alfonso, "Los medios de selección de empleados públicos", "Revista de Derecho Público, 2012-1, Empleo Público I, Rubinzal Culzoni Editores, Buenos Aires - Santa Fe, 2012 p. 133. Destaca como posición minoritaria la del Dr. Comadira, quien sostenía que la garantía de igualdad consagrada en el artículo 16 impone como regla constitucional la realización de concurso para los cargos de funcionarios no políticos.

Buteler observa que actualmente el artículo 16 no puede ser analizado en forma aislada, y considera relevante el contenido del artículo 75 inciso 23 de la Constitución Nacional al disponer la obligación al Congreso Nacional de legislar y disponer medidas de acción positiva que garanticen la igualdad real de oportunidades y de trato, lo que supone no ya, asegurar la igualdad formal, sino también substancial, para lo que el concurso tiene mucho que ver. Hace mención también a los instrumentos internacionales constitucionalizados por el artículo 75 inciso 22, en concreto el artículo 21 inciso 2 de la Declaración Universal de Derecho Humanos y el artículo 25 inciso c del Pacto Internacional de Derechos Civiles y Políticos.

COMADIRA, Julio, R., "Derecho Administrativo", Lexis Nexis - Abeledo Perrot, 2da. ed., Bs. As., 2003, nota 1383, p. 543.

40 Artículo 75 inciso 19 de la Constitución Nacional: “Corresponde al Congreso: .... 19) Proveer lo conducente al desarrollo humano, al progreso económico con justicia social, a la productividad de la economía nacional, a la generación de empleo, a la formación profesional de los trabajadores, a la defensa del valor de la moneda, a la investigación y al desarrollo científico y tecnológico, su difusión y aprovechamiento.

Proveer al crecimiento armónico de la Nación y al poblamiento de su territorio; promover políticas diferenciadas que tiendan a equilibrar el desigual desarrollo relativo de provincias y regiones. Para estas iniciativas, el Senado será Cámara de origen. 
categorías en particular en el inciso $23^{41}$ del mismo artículo. En esta última norma se mencionan como grupos objeto de protección especial a niños, mujeres, ancianos y personas con discapacidad, siendo que cada uno de estos grupos a su vez motivó la firma de diferentes convenios internacionales garantizando sus derechos.

La implementación de medidas tendientes a procurar el acceso a determinados derechos puede generar situaciones de discriminación inversa, lo que no necesariamente ocurre en todos los $\operatorname{casos}^{42}$-, aunque si es un supuesto el de la adopción de cupos en la administración pública para determinados grupos en situación de vulnerabilidad ${ }^{43}$.

Sancionar leyes de organización y de base de la educación que consoliden la unidad nacional respetando las particularidades provinciales y locales; que aseguren la responsabilidad indelegable del Estado, la participación de la familia y la sociedad, la promoción de los valores democráticos y la igualdad de oportunidades y posibilidades sin discriminación alguna; y que garanticen los principios de gratuidad y equidad de la educación pública estatal y la autonomía y autarquía de las universidades nacionales.

Dictar leyes que protejan la identidad y pluralidad cultural, la libre creación y circulación de las obras del autor; el patrimonio artístico y los espacios culturales y audiovisuales".

41 Artículo 75 inciso 23 de la Constitución Nacional: "Corresponde al Congreso: ... 23): Legislar y promover medidas de acción positiva que garanticen la igualdad real de oportunidades y de trato, y el pleno goce y ejercicio de los derechos reconocidos por esta Constitución y por los tratados internacionales vigentes sobre derechos humanos, en particular respecto de los niños, las mujeres, los ancianos y las personas con discapacidad.

Dictar un régimen de seguridad social especial e integral en protección del niño en situación de desamparo, desde el embarazo hasta la finalización del período de enseñanza elemental, y de la madre durante el embarazo y el tiempo de lactancia".

42 GELLI, María Angélica, "Constitución de la Nación Argentina. Comentada y concordada", 4ta. Edición ampliada y actualizada, t. II., La Ley, Bs. As., 2008, p. 235.

43 MEDINA, Graciela, "Vulnerabilidad, control de constitucionalidad y reglas de prueba. Las 'categorías sospechosas': Una visión jurisprudencial", LL 2016-F, 872. La autora define: "La expresión 'grupos en situación de vulnerabilidad' se utiliza para designar a aquellos grupos de personas o sectores de la población que, por razones inherentes a su identidad o condición y por acción u omisión de los organismos del Estado, se ven privados del pleno goce y ejercicio de sus derechos fundamentales y de la atención y satisfacción de sus necesidades específicas".

Así también en las Reglas de Brasilia sobre acceso a la justicia de las personas en condición de vulnerabilidad" (adoptadas en Brasilia en la XIV Cumbre Judicial Iberoamericana llevada a cabo los días 4 a 6 de marzo de 2008) en la regla tercera se definió: "Se consideran 
El establecimiento de cupos para categorías de personas desaventajadas, si bien es una excepción a la garantía absoluta de igualdad con base en la idoneidad, tiene por objetivo cumplir con otro escalón, cual es el de la igualdad real de oportunidades, tanto para quienes no se encuentren en condiciones psicofísicas o socioeconómicas semejantes, como para quienes, por prejuicios culturales, actualmente -en este caso hasta que exista una conciencia pública internalizada y generalizada- se encuentren en una situación de inferioridad - o de exclusión - para acceder a un puesto de trabajo.

Frente a cada grupo diferenciado hay que sopesar la razonabilidad y proporcionalidad entre el sacrificio del derecho de quienes no entran en la categoría frente a la necesidad de favorecer la igualdad de oportunidades de quienes sí están incluidos; asimismo dentro de este último grupo cabe verificar el respeto del principio de idoneidad ${ }^{44}$

Aquí no está en juego la exigencia de idoneidad, ya que en cada categoría deberá respetarse tal imperativo estructural, sino que frente a cada grupo diferenciado corresponde sopesar la razonabilidad de la distinción para verificar el respeto de la garantía de igualdad.

En nuestro país se han adoptado políticas destinadas a brindar igualdad real de oportunidades a determinados grupos diferenciados.

Por un lado, a través de planes sociales de empleo destinados a la reinserción laboral, tal el caso, a nivel Nacional, del programa denominado "Hacemos Futuro" 45 cuyo objetivo es dotar a los beneficiarios de los planes de preparación educativa

\footnotetext{
en condición de vulnerabilidad aquellas personas que, por razón de su edad, género, estado físico o mental, o por circunstancias sociales, económicas, étnicas y/o culturales, encuentran especiales dificultades para ejercitar con plenitud ante el sistema de justicia los derechos reconocidos por el ordenamiento jurídico". Fuente página web: http://www.acnur.org/fileadmin/scripts/doc.php?file=fileadmin/ Documentos /BDL/2009/7037).

44 GELLI, María Angélica, “Constitución Nacional...", op. cit. P. 236.

45 Resolución n96/2018 del Ministerio de Desarrollo Social de la Nación.
} 


\title{
y formación práctica para estar en mejores condiciones para acceder al mercado laboral ${ }^{46}$.
}

\author{
Por el otro, el Estado prevé la cobertura de un porcentaje \\ del plantel de su organización para determinadas catego- \\ rías, tal el caso de las personas con capacidades especiales ${ }^{47}$,
}

46 Artículo $2^{\circ}$ de la resolución 96/18 del Ministerio de Desarrollo Social de la Nación: "Créase el "PROGRAMA HACEMOS FUTURO" en la órbita de la SECRETARÍA DE ECONOMÍA SOCIAL cuyo objetivo es empoderar a las personas o poblaciones en riesgo o situación de vulnerabilidad social, promoviendo su progresiva autonomía económica a través de la terminalidad educativa y cursos y prácticas de formación integral que potencien sus posibilidades de inserción laboral e integración social".

47 Artículo 8 de la Ley 10592 de la Provincia de Buenos Aires (Texto según Ley 14968): "El Estado Provincial, sus organismos descentralizados, las empresas del Estado, las municipalidades, personas jurídicas de derecho público no estatal creadas por Ley, las empresas subsidiadas por el Estado y las empresas privadas concesionarias de servicios públicos, están obligados a ocupar personas con discapacidad que reúnan condiciones de idoneidad para el cargo, en una proporción no inferior al cuatro (4) por ciento de la totalidad de su personal y a establecer reservas de puestos de trabajo a ser ocupados exclusivamente por ellas, de acuerdo con las modalidades que fije la reglamentación.

Resérvense, además, las vacantes que se generen en los cargos correspondientes a los agentes que hayan ingresado bajo el régimen de la presente Ley, o que posteriormente se hayan incorporado a esta norma, para ser ocupadas en su totalidad y exclusivamente por personas con discapacidad, de acuerdo a las condiciones de idoneidad previamente referidas. Dichas vacantes, no estarán sujetas a vulneración alguna en relación a su efectiva disponibilidad.

El porcentaje determinado en el primer párrafo será de aplicación sobre el personal de planta permanente, temporaria, transitoria y/o personal contratado cualquiera sea la modalidad de contratación. Asimismo, y a los fines del efectivo cumplimiento del mínimo establecido, todos los Entes enunciados en el párrafo precedente, deberán comunicar a la Autoridad de Aplicación el relevamiento efectuado sobre el porcentaje aquí prescripto, precisando las vacantes existentes y las condiciones para el puesto o cargo que deba cubrirse".

Artículo 43 de la Constitución de la Ciudad Autónoma de Buenos Aires: "La Ciudad protege el trabajo en todas sus formas. Asegura al trabajador los derechos establecidos en la Constitución Nacional y se atiene a los convenios ratificados y considera las recomendaciones de la Organización Internacional del Trabajo. La Ciudad provee a la formación profesional y cultural de los trabajadores y procura la observancia de su derecho a la información y consulta.

Garantiza un régimen de empleo público que asegura la estabilidad y capacitación de sus agentes, basado en la idoneidad funcional. Se reconocen y organizan las carreras por especialidad a las que se ingresa y en las que se promociona por concurso público abierto. Asegura un cupo del cinco por ciento del personal para las personas con necesidades especiales, con incorporación gradual en la forma que la ley determine. En todo contrato de concesión de servicios o de transferencia de actividades al sector privado, se preverá la aplicación estricta de esta disposición. 


\section{liberados ${ }^{48}$ o pertenecientes al colectivo $\mathrm{LGTB}^{49}$. Así también}

Reconoce a los trabajadores estatales el derecho de negociación colectiva y procedimientos imparciales de solución de conflictos, todo según las normas que los regulen.

El tratamiento y la interpretación de las leyes laborales debe efectuarse conforme a los principios del derecho del trabajo".

Artículo 8 de la Ley 9325 de la Provincia de Santa Fe: "El Estado Provincial, sus organismos descentralizados o autárquicos, los entes públicos no estatales, las empresas del Estado Provincial, están obligadas a ocupar personas discapacitadas que reúnan condiciones de idoneidad para el cargo en proporción preferentemente no inferior al $4 \%$ de la totalidad de su personal. El Ministerio de Salud y Medio Ambiente de la Provincia fiscalizará lo dispuesto en el presente artículo".

Artículo 1 de la Ley 1502/04 de la Ciudad Autónoma de Buenos Aires: “Objeto. La presente Ley tiene por objeto regular la incorporación, en una proporción no inferior al cinco (5) por ciento, de personas con necesidades especiales al Sector Público de la Ciudad Autónoma de Buenos Aires, a fin de dar cumplimiento a lo dispuesto en el artículo 43 de la Constitución de la Ciudad Autónoma de Buenos Aires".

48 Artículo 178 de la Ley 12256 de la Provincia de Buenos Aires: "La legislación que establezca y regule la actividad laboral para el empleado público provincial, como así también la de los entes autárquicos y/o descentralizados, deberá prever la ocupación laboral de los liberados, mediante la reserva para tal fin de un tres (3) por ciento del total de los puestos de trabajo, en la forma que determine la reglamentación. Se invita a cada Municipalidad a adoptar similar criterio al establecido en el presente".

Artículo 1 de la Ley 14301 de la Provincia de Buenos Aires: “El Estado Provincial, sus organismos descentralizados y las empresas del Estado, con las salvedades que establezca la reglamentación, están obligados a ocupar a los liberados con domicilio o residencia en territorio provincial que hayan cumplido más de cinco (5) años de privación de libertad y reúnan las condiciones de idoneidad para el cargo y de ingreso en los términos del artículo $3^{\circ}$ inciso b) de la Ley 10.430 (T.O. por Decreto 1869/96), en una proporción no inferior al dos por ciento (2%) de la totalidad de su personal; y a establecer reservas de puestos de trabajo a ser ocupados exclusivamente por ellos, de acuerdo con las modalidades que fije la reglamentación.

Se dará prioridad de ingreso a aquellos liberados que hayan resultado sobreseídos o absueltos.

El porcentaje determinado en el primer párrafo será de aplicación sobre el personal de planta permanente, temporaria, transitoria y/o personal contratado cualquiera sea la modalidad de contratación. Asimismo y a los fines del efectivo cumplimiento del mínimo establecido, todos los Entes enunciados en el primer párrafo, deberán comunicar a la Autoridad de Aplicación el relevamiento efectuado sobre el porcentaje aquí prescripto, precisando las vacantes existentes y las condiciones para el puesto o cargo que deba cubrirse".

Lo subrayado de encuentra observado por el Decreto de Promulgación n 1322/11, de la Ley. 49

Numerosas jurisdicciones locales han abordado la necesidad de acceso al trabajo de las personas relegadas por su identidad de género autopercibido, estableciendo cupos y, en algunos casos con políticas de promoción de empleo en el ámbito privado a través de beneficios económicos. En la Ciudad Autónoma de Buenos Aires en el año 2012 se dictó la Ley 4573 que establece la "Política Pública para el reconocimiento y ejercicio pleno de la ciudadanía de las personas Lesbianas, Gays, Trans, Bisexuales e Intersexuales (LGTBI)". En su artículo 5 
inc c propone la incorporación de un porcentaje no inferior al $5 \%$ del colectivo trans al sector público, entendido éste como comprensivo de todos los organismos del Estado.

En la provincia de Buenos Aires, por Ley 14783 de 2015 -denominada "Ley Diana Sacayán" por ser una iniciativa de dicha líder travesti y activista por los derechos humanos -, el sector público provincial debe ocupar el $1 \%$ de los puestos de trabajo, concepto abarcativo del Estado Provincial, sus organismos descentralizados, las empresas del Estado, las municipalidades, personas jurídicas de derecho público no estatal creadas por Ley, las empresas subsidiadas por el Estado y las empresas privadas concesionarias de servicios públicos (Artículo 2 de la norma).

La provincia de Chubut, conforme lo dispone la Ley $N^{\circ}$ I N621 de 2018, destina el 0,5\% de los cargos a ocupar del sector público provincial entendido este como el Estado Provincial, sus organismos descentralizados, las empresas del Estado, sociedades anónimas con participación estatal mayoritaria, sociedades de economía mixta y todos aquellos organismos empresariales donde la Provincia tenga participación mayoritaria en el capital (artículo 3 de la norma), por otro lado por el artículo 8 se invita a los municipios a adherir a la ley.

La Ley N 5328 de 2018 de la provincia de Río Negro prevé ocupar el 1\% de su personal en la administración pública provincial invitando a adherir tanto a los Municipios (artículo 13) como a los Poderes Legislativo y Judicial (artículo 14).

En la provincia de Chaco por Ley 2934-L en el año 2018 se sanciona el régimen de "Promoción de la inserción y la participación en la vida social, económica, política y cultural de personas travestis, transexuales y transgénero", allí no se estableció un cupo sino reglas para la cobertura de cargos en el sector público provincial, integrado por todos los organismos estatales contemplados en la Ley de Administración Financiera provincial, estableciendo en el artículo 4 una presunción a favor de la idoneidad de las personas trans, así también prevé el cumplimiento de la exigencia al realizar contrataciones con concesionarios o transferencias de cometidos al sector privado. Es de destacar el artículo 7 que otorga beneficios impositivos a particulares que contraten personas trans, ya que tendrán derecho en el primer año de la contratación, a una bonificación en el impuesto a los Ingresos Brutos equivalente al importe mensual abonado por el empleador en concepto de Contribuciones al Sistema de Jubilaciones y de Obra Social por cada persona contratada, la cual será acumulativa, siempre que en total no supere el diez por ciento, del anticipo mensual devengado en el Impuesto a los Ingresos Brutos.

Asimismo, independientemente de la existencia de un marco legal provincial, muchos municipios dictaron ordenanzas asignando un cupo al colectivo trans, tales como: Almirante Brown, Avellaneda, Lanús, Merlo, Morón, Quilmes, San Miguel, Tres de Febrero, San Isidro, Chivilcoy, Azul, Ramallo y Mar del Plata adhiriendo al cupo de la Ley de la provincia de Buenos Aires - sin perjuicio que, por el artículo 2 de la Ley 14783 las comunas están obligadas a cumplirla-, a las que se suman Pilar y Florencio Varela con normas específicas que instituyen el cupo.

En el resto de las provincias los siguientes municipios han previsto cupos: Santo Tomé, Capitán Bermúdez, Chañar Ladeado, Rosario, San José del Rincón, Gálvez, San Justo, Venado Tuerto y Ciudad de Santa Fe (Santa Fe) San Pedro (Jujuy); Fray Mamerto Esquiú (Catamarca); Resistencia (Chaco, antes de la ley provincial); Bell Ville. (Córdoba); Orán y Salta (Salta); Santa Rosa (La Pampa); Cinco Saltos, Bariloche, San Antonio Oeste, Cipolletti, Luis Beltrán, Río Colorado, Viedma (Río Negro, antes de la ley provincial); Las Heras y Luján de Cuyo (Mendoza); Villa Mercedes (San Luis); Tafí del Valle (Tucumán); Río Grande (Tierra del Fuego)

\section{6 | ENSAYOS}


se ha propuesto el reconocimiento de un cupo general para aquellos que se encuentren en situación de vulnerabilidad ${ }^{50}$.

Considero que el mayor condicionante para acceder a un empleo es la indigencia, en general acentuado por la falta de capacitación, tal situación constituye un agravante para cualquier grupo desaventajado, ya que, no es lo mismo que cualquiera de las personas que se encuentren en un grupo calificado como desaventajado -a su vez- sea pobre; tampoco son iguales las posibilidades de cualquier hombre pobre respecto de quien no lo es.

Asimismo, dentro de cada cupo previsto, el criterio de selección debe ser el de la idoneidad en sus diferentes facetas; éste es un requisito esencial que permite elegir con parámetros racionales, limitando la discrecionalidad y asegurando un desempeño laboral potencialmente apto.

\section{Respuesta jurisprudencial al reclamo de ingreso a la administración pública}

\section{1) Sentencias garantizando la exigencia de concurso como requisito de regularidad de los actos o declarando la inconstitucionalidad de normas que eluden el concurso}

a) Inconstitucionalidad de normas que prevén mecanismos de selección sin considerar la idoneidad. Ingreso hereditario

- Corte Suprema de Justicia de la Provincia de Santa Fe (Reg.: A y S t 204 p 254-267), en sentencia del 29 de diciembre

La ciudad de Rosario ha dado cumplimiento al régimen adoptado por la Ordenanza 9543 de Inclusión a la planta administrativa de trabajadores municipales de personas travestis, transexuales y transgénero; dicha norma fue reglamentada por decreto municipal 83 del 13 de enero de 2017. Así también ha desarrollado políticas de inclusión laboral en el sector privado a través de convenios con empresas, por los que se brinda trabajo a personas pertenecientes a grupos priorizados, entre ellos del colectivo trans.

50 Expediente 2875/15 Senado De La Nación Proyecto De Ley Negre de Alonso y Rodriguez Saa.: Proyecto de Ley de cupo laboral para colectivos vulnerables y creación del Consejo Federal de Inclusión por el Trabajo. El expediente fue enviado al archivo el 15.3.2017. (fuente página web: www.senado.gov.ar). 
de 2004 en los autos caratulados "KEAODEELERT, Petchsamorn Phommachan de contra MUNICIPALIDAD DE CORONDA Sobre RECURSO CONTENCIOSO ADMINISTRATIVO DE PLENA JURISDICCIÓN" (Expte. C.S.J. nro. 193 del año 1995).

- Corte Suprema de Justicia de la Provincia de Santa Fe, Reg.: A y S t 207 p 334-340, sentencia del 8 de junio de 2005 en los autos caratulados "NAVARRETE, Filomena Susana contra COMUNA DE BERNABÉ MOLINA sobre RECURSO CONTENCIOSO ADMINISTRATIVO DE PLENA JURISDICCIÓN" (Expte. C.S.J. no 673, año 1995).

- Cámara de lo Contencioso Administrativo $\mathrm{n}^{\circ} 1$ de Santa Fe (A y S, tomo 37, pág. 197/205), sentencia del 18 de febrero de 2014 en la causa CCA 1 n²84 año 2009 caratulada "SANTILLÁN, Paola Maricel contra MUNICIPALIDAD DE SAN JAVIER sobre RECURSO CONTENCIOSO ADMINISTRATIVO".

En todos los casos, ante la pretensión de quien solicita ingresar a la administración comunal por su condición de familiar de un ex agente fallecido, invocando el derecho que le reconocería el artículo 130 de la Ley 9286, declara la inconstitucionalidad de esta norma por ser violatoria del requisito consagrado por el artículo 16 de la Constitución Nacional.

\section{b) Legitimación a agentes para cuestionar la regularidad} de cobertura de cargos sin concurso

Cámara de lo Contencioso Administrativo n ${ }^{\circ} 1$ de Santa Fe, Sentencia del 6 de noviembre de 2008 en autos caratulados "DI MARTINO, Fernando A.; DI SANTE, Rubén R.; ABELLEYRA, José A.; GARCILAZO, Raúl F. y AGUILAR, Víctor H. contra PROVINCIA DE SANTA FE sobre RECURSO CONTENCIOSO ADMINISTRATIVO" (Expte. C.C.A.1 n ${ }^{\circ}$ 81, año 2005).

Se hace lugar al recurso interpuesto por agentes que impugnan el decreto de designación de otros agentes por no cumplirse con el requisito de concurso previo en la cobertura de ascensos al aprobar una nueva estructura orgánico funcional. 
c) Reconocimiento de legitimación a personas que no integran la planta de la administración para exigir la regularidad del procedimiento de ingreso a la misma

Cámara de lo Contencioso Administrativo $\mathrm{n}^{\circ} 1$ de Santa Fe, Reg.: A. y S. T. 6, pág. 258. Sentencia del 20 de octubre de 2006 en causa CCA 1 n $^{\circ} 389$ del año 2006 caratulada "TIRONI, Laura Noemí y otros contra PROVINCIA DE SANTA FE sobre MEDIDA CAUTELAR AUTÓNOMA".

En el caso, si bien se rechaza la medida cautelar solicitada por beneficiaros de planes jefes y jefas de hogar para suspender la ejecución de un acto de designación de agentes, en el voto del Dr. Lisa, se reconoce legitimación a los actores en un proceso de mayor debate y prueba, estableciendo que, cualquiera sea la naturaleza jurídica de la relación en virtud de la cual los peticionarios prestarían servicios en la Provincia, dicha sola prestación resulta en principio idónea a los fines de la invocación de un interés legítimo al ingreso a la planta permanente; es decir, diferenciado del simple interés de los restantes miembros de la comunidad.

d) Sentencias reconociendo a la idoneidad como un piso que no exige necesariamente la selección del postulante más idóneo

CSJN, sentencia del 9 de noviembre de 2017 en causa FSA 2445/2016/CS1-Cal caratulada "Galíndez, Nicolás Emanuel el Ministerio Público Fiscal de la Nación si amparo ley 16.986. Fallos: 340:1581

El Máximo Tribunal interpreta que la exigencia de idoneidad para cubrir los cargos públicos debe interpretarse como un umbral mínimo que debe superarse, lo cual no impide que la reglamentación establezca criterios de selección más exigentes.

Se señala que de dicha norma no se sigue que deba preferirse, entre varios candidatos, a aquel que demuestre tener la mayor capacidad intelectual o técnica. Ello es así, porque no ha consagrado el derecho exclusivo del más capacitado de 
los aspirantes, sino, simplemente, el derecho de todos los que reúnan las exigencias mínimas de idoneidad que se hubieran previsto. Todos estos son, en palabras de la Constitución, "admisibles en los empleos".

\section{2) Sentencias que examinan la estabilidad de trabajadores que ingresaron irregularmente a la administración}

a) Reconocimiento de estabilidad a personal que pasa de planta temporaria a permanente sin concurso

CSJN - Fallos 338:212, sentencia del 25 de marzo de 2015 en causa CSJ 35/2013 (49-K)/CS1 "Kek, Sergio Leonardo y otros c/ Municipalidad de Coronel Du Graty s/ demanda contencioso administrativa".

La Corte no revocó el acto de designación de personal transitorio como permanente, teniendo en cuenta las circunstancias del caso.

Por un lado, sostuvo que la exigencia de concurso para acceder a este tipo de cargos no surge con claridad de las normas que rigen el ingreso a la administración comunal.

Por otro, expresa que la ordenanza cuestionada tuvo la intención de cumplir con la manda constitucional del artículo 14 bis de la Constitución Nacional teniendo en cuenta que, según el criterio adoptado por esta Corte en Fallos: 333: 311 ("Ramos"), la conducta de la municipalidad podría haber generado en los actores una legítima expectativa de permanencia laboral.

b) Revocación del acto de designación como personal permanente al personal de planta temporaria sin concurso exigido expresamente

CSJN, sentencia del 14 de noviembre de 2017 en causa CSJ 275/2015/RHl caratulada "Aladín, Gerardo Ornar el Municipalidad de la Ciudad de San Francisco si acción contencioso administrativa". 
El Máximo Tribunal considera como un vicio grave la no realización del concurso cuando ello sea un requisito contemplado expresamente en la Constitución provincial y en el régimen de empleo público municipal aplicable.

c) Reconocimiento de incorporación a la planta permanente a personal incluido en programas especiales previos

Superior Tribunal de Justicia de Chaco en causa $n^{\circ} 2171 / 16-$ SCA/16 caratulada "Montiel, Roxana Noemí vs. Gobierno de la Provincia de Chaco s. Acción de amparo".

A través de una acción de amparo la actora requirió su incorporación a planta permanente por parte de la Provincia en cumplimiento de los requerimientos dispuestos por Ley 6655 de Chaco y, si bien la denegación de tal beneficio se funda en la posición que alcanzó en el orden de mérito del concurso de antecedentes y oposición, ya que quedó número 23, cuando las vacantes a cubrir eran 19, la Corte determinó que no es justificativo la ausencia de vacantes, ya que el art. 9 de la norma establece en modo imperativo que, en caso de ser necesario, el Estado creará los cargos, para cumplir con los objetivos de la ley.

\section{3) Reconocimiento de legitimación para exigir el concurso} y mantener el cargo ante una designación irregular ante la falta de cobertura de cargos

- Tribunal Superior de Justicia de la Ciudad Autónoma de Buenos Aires, Resolución del 5 de julio de 2005 en causa $\mathrm{n}^{\mathrm{o}} 3827 / 05$ caratulada "Corne, Roberto Miguel c/ GCBA s/ amparo (art. 14, CCABA) s/ recurso de inconstitucionalidad concedido.

El Máximo Tribunal declaró mal concedido el recurso y mantiene la sentencia que ordenara al Gobierno a que reincorpore al actor como empleado interino hasta tanto sustancie el concurso público para cubrir el cargo.

- Cámara de Apelaciones en lo Contencioso Administrativo y Tributario, Sala II, sentencia del 26 de mayo de 2011 
en causa $n^{\circ} 24871$ caratulada "Cecotti, Alicia María c /GCBA s/ Acción meramente declarativa".

Se reconoce el derecho de permanecer como personal de planta temporaria hasta que se realice el concurso pertinente en un plazo razonable a criterio de la administración.

\section{4) Derecho a exigir un concurso}

Cámara de Apelaciones en lo Contencioso Administrativo con asiento en San Nicolás sentencia del 2 de julio de 2010 en causa 808/2009 caratulada "Aires, Walter Darío c/ Dirección General de Cultura y Educación s/ Pretensión Anulatoria".

Reconoce el derecho a exigir la realización de un concurso para cubrir un cargo vacante ante la falta de convocatoria de la Administración pública.

\section{5) Reconocimiento de legitimación para exigir el ingreso a los cuadros de la administración}

a) Reconocimiento de legitimación a las personas con necesidades especiales

- Tribunal Superior de Justicia de la Ciudad Autónoma de Buenos Aires, sentencia del 14 de septiembre de 2005 en causa n $3771 / 05$ caratulada "Tobías Córdova, Álvaro Juan María s/ queja por recurso de inconstitucionalidad denegado en: 'Tobías Córdova, Álvaro Juan María c/ GCBA s/ amparo (art. 14 CCABA)'”.

Rechazó la queja y confirma la sentencia recurrida por la que se ordenaba a la Administración - en el área de informáticaa que se tenga en cuenta en la selección del personal al actor, circunscribiéndose a aquellos organismos en que no se haya cumplimentado el cupo dispuesto en el art. 43 de la Constitución de la Ciudad Autónoma de Buenos Aires.

- Tribunal Superior de Justicia de la Ciudad Autónoma de Buenos Aires, resolución del 29 de noviembre de 2010 en causa $\mathrm{n}^{\circ} 7571 / 10$ "GCBA s/ queja por recurso de inconstitucionalidad denegado en 'Abdala, Jorge c/ GCBA s/ amparo (art. 14, CCABA)"”. 
Rechaza -por mayoría- la queja y, como consecuencia, mantiene la sentencia de la Sala II de la CCAyT que había ordenado reincorporar a la planta transitoria a una persona con capacidades especiales hasta tanto se realicen los concursos públicos y abiertos.

- Sentencia del 5 de abril de 2006 en la causa B. 62.599, "R., L. N. contra Provincia de Buenos Aires (Ministerio de la Producción). Demanda contencioso administrativa"

Por mayoría se hace lugar a la demanda reconociendo el derecho de la actora como aspirante a la cobertura del cupo fijado por el art. 8 de la ley 10.592, y condenando a la demandada a que, teniendo en cuenta los restantes requisitos fijados por dicha normativa y en cuanto sean compatibles con las premisas señaladas por la ley 10.430 , dicte un nuevo acto.

- Sentencia del (A y S, tomo 34, pág. 208/222) 26 días de agosto del 2013 en causa C.C.A.1 n 316, año 2007 caratulada "Duarte, María Eugenia contra Provincia de Santa Fe s/ Recurso Contencioso Administrativo".

Reconoce el derecho de la actora al ingreso a la Administración de conformidad a lo dispuesto en el artículo 8 y siguientes de la ley 9325; y ordena a que en el término de 60 días la Administración proceda a la incorporación de la recurrente -vía contratación- en un puesto acorde con sus capacidades y limitaciones personales, previa evaluación de su idoneidad, en cualquiera de los organismos dependientes del Estado provincial, hasta tanto se convoquen a concursos públicos de ingreso en las condiciones a que refiere la ley 9325 .

\section{2) Reconocimiento de legitimación amplia para exigir el cumplimiento de las normas que garantizan el cupo de cobertura de cargos para las personas con necesidades especiales}

- TSJ CABA, Sent. del 4/11/2009 en causa no 6603/09 caratulada "Barila Santiago c/ GCBA s/ amparo (art. 14 CCABA).

En el caso se reconoció legitimación activa a quien no era afectado directamente para reclamar la cobertura del cupo para 
discapacitados en el Gobierno de la Ciudad Autónoma de Buenos Aires, sin embargo hizo lugar al recurso de queja presentado por la demandada revocando la decisión de la Cámara de exigir a que en el plazo de sesenta días se tomen las medidas concretas y efectivas para cubrir dicho cupo, informando las mismas como también las medidas que debía implementar hacia futuro para cumplir con el mismo fin.

Remitió nuevamente la causa a la Cámara para que se dicte un nuevo pronunciamiento en el que se debe precisar las obligaciones concretas del demandado luego del cruzamiento de información para determinar las vacantes disponibles y los postulantes inscriptos lo que permitiría definir el eventual universo de beneficiarios y permitir la eventual ejecución de sentencia, limitando la actuación en esta etapa al actor en la causa por su condición de no afectado directo.

- Cámara de Apelación en lo Contencioso Administrativo y Tributario de la CABA, resolución del 14 de abril de 2011 en causa $n^{\circ}$ 22076-0 caratulada "Barila, Santiago c/ GCBA s/ Amparo (Art. 14 CCABA)"

Ante su nueva intervención, la Cámara ordenó al Gobierno de la CABA a sustanciar, dentro de los sesenta días de la firmeza de la decisión judicial, los concursos entre las personas inscriptas en el Registro Único Laboral para Aspirantes con Discapacidad a Empleo Público de COPIDIS (Comisión para la Plena Participación e Inclusión de las Personas con Discapacidad), observando el requisito de idoneidad; así también que las futuras contrataciones lo haga con personas inscriptas en el registro, entre otras cuestiones.

\section{Conclusión}

La articulación de la garantía de igualdad y el derecho a acceder por idoneidad ${ }^{51}$ a un cargo público consagrados

51 En sus diferentes facetas: Psicofísica, funcional, técnica y moral (tanto negativa como
positiva). 
en el artículo 16 de la Constitución Nacional -respecto de la totalidad de los habitantes de la república- supone, no solo el reconocimiento de un derecho exigible para cada uno de ellos, sino la consagración de un deber de tipo estructural para el Estado, que se encuentra en las bases del sistema de gobierno definido en nuestra Carta fundamental.

En nuestro país el sistema republicano exige que el gobierno del pueblo, como mínimo en los cuadros organizacionales de los tres poderes del Estado, se cubra mediante mecanismos de selección que les abra las puertas a todos sus habitantes en un pie de igualdad y con la exigencia ineludible de elegir sobre la base de su idoneidad ${ }^{52}$.

Otra es la discusión respecto de la normalización laboral de los cientos de miles de cargos asignados irregularmente (ya sea con o sin estabilidad) y las distintas soluciones jurídicas, sociales o políticas que se adopten hacia el pasado; pero, hacia adelante, y como política de estado -independientemente de la orientación política que la dinámica de la periodicidad democrática impone-, debe exigirse el respeto absoluto a esta exigencia Constitucional prevista hace más de ciento sesenta años como una decisión basamental para la construcción, desarrollo y crecimiento de nuestro país.

\footnotetext{
52 ZINGARETTI, Gisela, "La idoneidad en la función pública con especial referencia al empleo público", Revista de Derecho Público, 2012-2, Empleo Público II, Rubinzal Culzoni Editores, Buenos Aires - Santa Fe, 2012, p. 167. Observa que el artículo 16 de la Constitución Nacional recepta el pensamiento de Montesquieu relativo a la "virtud republicana" mediante la conjugación política de los principios de igualdad y aptitud.
} 